\title{
Study on the Relevance between Environmental Factors and the Respiratory System Disease
}

\author{
RU Li-xian \\ school Hospital, Qilu Industrial University, Jinan , 250100, China. \\ email:rulixian1978@163.com
}

Keywords: Environmental factors; Respiratory system diseases; The correlation

\begin{abstract}
Purpose: To understand the effect of atmospheric pollution, house decoration and Smoke exposure on the clinic casesof respiratory system disease , investigate the relationship between environmental factors and the respiratory system disease. Methods: To Survey the situation of patient's smoke exposure and household decoration, who are diagnosed upper respiratory tract infection, bronchitis, bronchial asthma, allergic rhinitis, chronic obstructive pulmonary disease in 2014 January to December, collect this stage from the local environmental protection agency and the meteorological data of meteorological department. Analyze 5 kinds of respiratory disease cases of doctor visits, atmospheric pollution degree, temperature changes, and compare the correlation between the API and sufferings disease cases, between temperature and disease cases, between smoke exposure ,household decorates and the characteristics of disease. Results: The results showed that Smoke exposure and 5 kinds of respiratory disease had relevance, especially with chronic obstructive pulmonary disease, household decorates had close ties to the bronchial asthma and allergic rhinitis, API index , bronchitis, bronchial asthma, and upper respiratory tract infections were positively correlated, allergic rhinitis had closely associated with seasonal, respiratory infections and chronic obstructive pulmonary disease had closely related to the temperature change.
\end{abstract}

\section{Introduction}

Environment is essential to the survival of humans, both natural environment, geographical environment, and indoor household environment . The environment is also the important factor deciding to human health and development . Especially in recent years, The threat of environmental pollution on human health makes the study on correlation between environmental factors and health research has received the unprecedented attention. With the raise of exposure science[1], the study of the environmental exposure also is becoming more and more attention . Environmental exposure is the important fields to connect with traditional science, such as environmental science, toxicology, epidemiology, health science, and risk assessment, pollutants environmental behavior, health effects, and exposure to risk and early warning research focus should be the same hot spot , especially the children's health[2]. Approaches of environmental exposure is breathing, eating, skin, and through breathing exposure is the main way . The respiratory system is the key to maintain life, and is the main channel to contact with the body and the outside environment. So the influence of environmental factors on the respiratory system health is the biggest, especially some chronic respiratory diseases, such as chronic obstructive pulmonary disease, chronic bronchitis, and some allergic diseases, including asthma and allergic rhinitis. This article mainly makes a tentative discussion on the correlation of between environment and common respiratory system diseases through outpatient questionnaire survey method, in order to base for further research.

\section{Materials and methods}

1. Object: respondents are from the tutor respiratory clinic patients in January 1, 2014 to January 1, 2015, who are diagnosed with bronchitis, breathe the infection on, bronchial asthma, allergic rhinitis, and chronic obstructive pulmonary disease [3-7] . 


\section{Methods}

2.1 The establishment of questionnaire: questionnaire was drawn up according to project design, the content including patients with general information, clinical time, common respiratory diseases, including upper respiratory tract infection, allergic rhinitis and bronchial asthma, chronic bronchitis, chronic obstructive pulmonary disease, and the average temperature, air quality, smoke exposure, household situation (mainly refers to presence of decorate house within a month) .

2.2 Air quality: The air pollution index (API) as the main reference index, according to the GB3095-2012 [8] the environment air quality standards. With the size of the API , air quality is good in $0 \sim 100$, light pollution in $101 \sim 200$, moderate pollution in $201 \sim 300$ for, severe pollution in greater than 300 .API is derived from the local environmental testing department announced that day.

2.3 The temperature data: record data is the average daily air temperature, the average algorithm is the high temperature and low temperature.

2.4 Statistical methods: apply The SPSS 15.0 statistical software to statistical analysis, normal distribution data using $X+s$, classification data calculation by composition ratio and rate.To compare the correlation between API the temperature and the number of clinic cases respectively of 5 kinds of respiratory system diseases ,calculating correlation coefficient, by $\alpha=0.05$ for inspection standard.

\section{Results}

\section{The analysis of basic situation}

1.1 Patients basic information: this time included 2856 patients with doctor visits, the age of 17-85, with an average age of age $(45.6+6.1)$, with 1557 cases male patients, female patients 1398 cases, including smoking for 1245 cases of patients, often passive smoking of patients for 656 cases, 157 patients with newly household to decorate.the specific results are shown in table 1 .

1.2 Clinic diseases distribution: Cases of doctor visits the most were upper respiratory tract infection, the other four kinds of disease diagnosis cases of bronchitis, bronchial asthma, allergic rhinitis, chronic obstructive pulmonary disease. Specific results are shown in table 1.

1.3 Air quality situation analysis; according to the air quality standard five points method, there were no less than 50 , light pollution is given priority to, for the whole year a total of 161 days, good air quality in 111 days, the condition of the pollution in 52 days, severe and even serious pollution weather appeared 37 days. By month statistics, 1 month was with the worst air quality, with 15 days appeared high levels of pollution. Air quality is the best in July and August, good days accounted for more than half, and no severe pollution situation.

1.4 The analysis of temperature change : From the meteorological department reported data, temperature was an average of more than 30 degrees in May to August, belong to high temperatures, extreme high temperature all the year round in May 30, 39 degrees. On December and February, the average low temperature is below freezing, and the low temperature appeared in the February 9,10 degrees below zero.

\section{Correlation analysis among projects}

\subsection{The correlation between air quality and various disease cases}

Statistical results can be obtained from table 4, the correlation coefficient of API and the number of the clinic cases for $0.705, \mathrm{P}<0.01$, suggesting there was relevant. API and the medical case lagging of one day and three days also existed positive correlation, the correlation coefficient respectively for 0.531 and $0.257, \mathrm{P}<0$. 01. Different API group of disease diagnosis example 
number increased to different extent. API and upper respiratory tract infection, bronchitis, bronchial asthma, allergic rhinitis, chronic obstructive pulmonary disease were positive correlation, the correlation coefficient respectively for 0.301 and 0.251 and $0.184,0.192,0.203, \mathrm{P}<0.05$.

\subsection{The correlation between temperature and various disease cases}

From table 5, daily clinic cases and the average daily temperature had a certain relevance, the mean temperature between $18 \sim 28,5$ kinds of diseases clinic cases remain basically stable, and the mean temperature at around 3 degrees, disease clinic cases appeared obvious increase, especially when the temperature difference is very big. Statistical analysis, the temperature and the number of cases have relevant correlation, the correlation coefficient was $0.224, \mathrm{P}<0$. 05 . The most sensitive to temperature changes was the upper respiratory tract infection, increased significantly under $4{ }^{\circ} \mathrm{C}$.There were the correlation between temperatures and upper respiratory infection, bronchitis, chronic obstructive pulmonary disease, the correlation coefficient respectively for $-0.169,0.177,0.122, \mathrm{P}<0.05$ 。 There was negative correlation between temperatures and allergic rhinitis, bronchial asthma ,the correlation coefficient respectively - 0.294 and 0. 383, P $<0.05$.

\subsection{The correlation of smoke exposure, home environment and disease cases}

From the result of statistics in table 1, bronchitis patients was most in smoke exposure, while allergic rhinitis cases was lest, the total exposure rate of 5 kinds of disease was $66.6 \%$. Household decorate had the bigger correlation with bronchial asthma and allergic rhinitis, $16.4 \%$ of patients with bronchial household, $11 \%$ of allergic rhinitis patients lived in newly decorated conditions. The correlation with home decoration and other three kinds of respiratory disease was not big.

Table 1 patient's basic situation analysis

\begin{tabular}{llllll}
\hline diseases & cases & men & women & $\begin{array}{l}\text { Smoke } \\
\text { exposure }\end{array}$ & $\begin{array}{l}\text { Household } \\
\text { decorates }\end{array}$ \\
\hline bronchitis, & 983 & 592 & 391 & 798 & 12 \\
$\begin{array}{l}\text { Upper respiratory tract } \\
\text { infection, }\end{array}$ & 722 & 347 & 375 & 405 & 18 \\
bronchial asthma, & 475 & 249 & 226 & 323 & 78 \\
allergic rhinitis, & 408 & 210 & 198 & 186 & 45 \\
COPD & 268 & 159 & 109 & 189 & 4 \\
total & 2856 & 1557 & 1299 & 1901 & 157 \\
\hline
\end{tabular}

Table 2 different API group and clinic disease cases counts

\begin{tabular}{lrrrrrr}
\hline API & bronchitis & URI & & BA & AR & COPD \\
\hline $51 \sim 100$ & 3.9 & 3.5 & 1.2 & 3.3 & 0.8 \\
$101 \sim 200$ & 4.4 & 4.2 & 2.8 & 3.6 & 2.1 \\
$201 \sim 300$ & 6.2 & 6.6 & 3.8 & 5.2 & 4.7 \\
$\geqslant 300$ & 8.7 & 8.4 & 5.2 & 7.3 & 5.3 \\
\hline
\end{tabular}


Table 3 statistics of temperature change and disease day clinic cases

\begin{tabular}{lllllll}
\hline & $\begin{array}{l}\text { average } \\
\text { daily } \\
\text { temperature }\end{array}$ & bronchitis & UIR & BA & AR & COPD \\
\hline January & 3.5 & 5.9 & 4.5 & 2.4 & 1.4 & 1.4 \\
February & 2.5 & 6 & 4.7 & 2.4 & 1.9 & 1.4 \\
march & 13.5 & 1.2 & 0.8 & 1.7 & 2.6 & 1 \\
April & 18 & 1 & 0.5 & 1.5 & 2.9 & 0.4 \\
may & 24.5 & 0.7 & 0.4 & 0.7 & 0.2 & 0.2 \\
June & 25 & 0.7 & 0.4 & 0.7 & 0.2 & 0.3 \\
July & 28 & 0.7 & 0.5 & 0.5 & 0.3 & 0.7 \\
August & 26 & 1.2 & 0.9 & 0.5 & 0.3 & 0.6 \\
September & 22 & 1.5 & 1.1 & 0.5 & 0.4 & 0.3 \\
October & 17.5 & 2.7 & 1.9 & 0.9 & 0.7 & 0.5 \\
November & 9 & 3.1 & 3.2 & 1.2 & 0.8 & 1.3 \\
December & 1.5 & 6.7 & 5.1 & 2.6 & 1.8 & 1.5 \\
\hline
\end{tabular}

\section{Discussion}

\section{Atmospheric pollution factors and the respiratory system disease}

Air pollution has obvious effect on the incidence of respiratory disease [3.4], and the effect was positively correlated with concentration of air pollution [5.6] . Calderon [7] found that compared with the clean area children, children's respiratory tract mucous membrane air pollution area and a wide range of histopathological change in nasal mucosa, including a variety of respiratory tract cell damage, increased neutrophils and intercellular space particles increase. Elevated atmospheric concentration of fine particulate pollutants can cause disease emergency increase, especially respiratory illnesses related to chronic bronchitis, asthma, COPD[8]. Now, study Is much in PM10 and PM2.5 . PM10 has a significant influence on the respiratory system disease [9], while in the case of low temperature and temperature difference is bigger, PM10 will make bigger risk on the respiratory system disease [10]. Sigaud [11] found long exposure of the PM2.5can increase the susceptibility of respiratory bacteria, viruses, mail cause respiratory tract colonization bacteria and some conditional pathogenic bacteria to pathogenic bacteria, causing infection. At the same time ,it can cause damage of tracheal mucous cilia barrier, thus increase susceptibility of bacteria, reduce the bacterial clearance rate, and lead to respiratory infection [12] . Through clinical research, many experts also verified the atmospheric particulate matter can increase the risk of respiratory disease illness and death, Ya-juan zhang [13] found such as atmospheric PM10 concentration rise every $10 \mathrm{mu}$ g/m3 for respiratory disease the excess risk of death was $0.56 \%$. And Joel will be the six cities atmospheric PM2.5 monitoring data and daily mortality data comprehensive analysis, found that the average daily concentrations of PM2.5 rise 10 $\mathrm{mu} \mathrm{g} / \mathrm{m} 3$, the crowd, because COPD deaths rose $1.5 \%$ [14].

\section{Temperature and respiratory system disease}

That years of alternating seasons and the changing of hot and cold have an impact on seasonal diseases, also affect the body each system. Peng han [15] found such as winter respiratory outpatient increases with the increased number of cases with the API to the patient, the respiratory system disease and symptoms appear is closely related to the temperature. Ma Pan [16] through the comprehensive analysis of the four seasons of various meteorological elements such as pollutant concentration and the relationship between upper respiratory tract infection patients, found that spring feeling patients and negatively correlated with humidity and precipitation; Summer patients was positively correlated with average temperature, minimum temperature, and negatively correlated with maximum wind speed, autumn patients showed a negative correlation with 
temperature, precipitation, and kinds of pollutants concentration were positively correlated, winter patients and negatively correlated with temperature, relative humidity, rainfall, and air pressure were positively correlated, the contrast analysis, for three seasons spring, summer, winter, meteorological conditions on the cases on the dominant role, and the effect of ambient air quality than autumn.

\section{Indoor environment factors and the respiratory system disease}

With the advance of human socialization, and the change of life-style, modern people most of the time is spent indoors, so the influence of the indoor environment is more important than the natural environment, especially for children. This paper mainly study two elements, the smoke and decorate . The mechanism that smoking cause respiratory damage is still in the study, there is a recognized mechanism inflammatory reaction, oxidation and antioxidant imbalance, protease and resistance to protease imbalances. According to the survey, there are $61.9 \%$ smoking in the family of China youth. The rate of smoking families is higher than nonsmoking family in the aspect of coughing up phlegm, asthma, and the proportion of sore throat ,but no statistically significant difference, then cough was statistically significant between two groups of family teenagers; with respect to the proportion of respiratory disease , such as acute upper respiratory tract infections, pneumonia, asthma, pharyngitis and tonsillitis, Smoking family is higher than of not smoking family, but no statistically significant difference [17]. And the prevalence rate of respiratory system disease increase with the increase of smoking amounts [18]. The effect of bedroom decorates on human health is because all kinds of chemical synthesis used, such as formaldehyde, benzene, ammonia, etc., these can significantly increase the risk of asthma in children [19-21]. Such as the concentration of indoor formaldehyde every increase 1 unit (mu g/m3), can increase the risk of asthma in adults 0.02 times [22].

\section{Prospects}

Environmental factors can stimulate respiratory diseases onset, increase, even death. In recent years, because of the deterioration of the environment pollution and the appearance of haze days, it make attention for improvement of the environmental pollution. Human are also to actively respond to environmental pollution, such as green travel, reducing automobile exhaust emissions ,making some modification of polluting factories, reducing emissions of sulphur, etc., had achieved initial results , but the pollution of the environment problem is a long way to go. This paper is just the tip of the iceberg, will gradually in-depth research in the future.

\section{Conclusion}

Environment pollution plays a significant role in the pathogenesis of the respiratory system disease, temperature and the incidence of respiratory diseases have close relationship, especially in the extreme weather and temperature difference bigger.

\section{Reference}

[1]Barr D.Expanding the role of exposure science in environmental health[J].J Expo Sci Env Epid,2006,16,473-475.

[2] Environmental exposure science:a new inter discipline. Li Xiaoping . Foreing Medical Science Section of Medgeography .2016,37(2):81-84.

[3] WANG Hai-rong ,ZHAI Qiu-min, SHEN Juan. Impacts of Air Pollutants on the Respiratory System Diseases in A City. ENVIRONMENTAL SCIENCE AND MANAGEMENT,2011,36(3):54-57.

[4]HUANG Wen-shan, HU Heng-sheng, LIN Hang, et al. Study of the Relationship Air Pollution and Respiratory Diseases in Nanning.J Environ Health,2004,21(6):384-386. 
[5]MA Yan-jun, QI Li-li, YANG Hong-bing. Analysis to examine the effects of air pollution on the respiratory system disease. Liaoning meteorological,2002,(2):33-34.

[6]LI Ning, ZHANG Ben-yan, PENG Xiao-wu. Relationship between Air Pollution and Hospitalzation ofChildren Respiration Disease in Shenzhen City.Chin J Public Health,2009,25(12):1504-1505.

[7]Calderon-Garciduenas L, Valenciaa-Salazar G, Rodriguez-Alcaraz A, etal. Ulter as tructural nasalpathology in children chronically and sequentially exposed to air pollutants[J]. Am J Respir Cell Mol Biol,2001,24(2):132.

[8] ZHAI Wen-hui, HUANG Zhi-gang, LU Jing-kai ,et al. Association between Particulate Matters in the Ambient air Pollution and Hospital Emergency Treatment for Elderly Respiratory Diseasesin Beijing: A Case Crossover Study. Progress in Modern Biomedicine, 2015, 15(8):1461-1464.

[9] LIU Xin-chao, GUO Jie, SHEN Hui ,et al. Air pollution Effects on Children's Respiratory System Disease in Chengdu City.Plateau and Mountain Meteorology Research, 2015,35(3):84-87

[10]LI Guo-xing, TAO Hui, LIU Li-qun, et al. Interaction between Inhalable Particulate Matter and Apparent Temperature on Respiratory Emergency Room Visits of a Hospital in Beijing.J Environ Health, 2012,29(6): 483-486.

[11]Sigaud S, Goldsmith CA, Zhou H, et al. Air pollution particles dimish bacterial clearance in the pried lungs of mice[J].Toxicol appl Pharmacol,2007,223(1):1.

[12]Schikowski T ,Sugiri D, Ranft D, et al. Long-term air pollution expoture and living close to busy roads are associated with COPD in women[J].Respir Res,2015,6:152.

[13]ZHANG Ya-juan, ZHOU Jian,YIN Hong-lei,et al. Spatial-temporal analysis for correlation between ambient inhalable particles and Respiratory disease mortality in Beijing,china.J Environ Health, 2014,31(9):753-756.

[14]Joel S, Francine L, Antonella Z.The Concentration-Response Re-lation between PM2.5and Daily Deaths [J]. EnvironHealthPer-spec, 2002, 110(10):1025-1029.

[15]Han Peng, XU Zhi-qiang. Correlation Analysis of Respiratory Diseases in Respiratory Clinic with Air Quality and Temperature in Winter. Chin J R espir Crit Care Med, 2015,14(2):197-200.

[16]Ma Pan, Li Tan-shi, Ning Gui-cai, et al. Ralationship between upper respiratory tract infections and meteorological environmental conditions in Beijing City. Journal of Lanzhou University, 2015,51(1):79-86.

[17]ZHANG Jin-rong. Affect of tobacco smoke indoors on the health of respiratory system of teenagers in Baicheng city. Community Medical Journal, 2016,14(15):83-84.

[18]WANG Zhen-quan, LI Sheng,-WEI, XUE ling, et al. Effect of House Indoor Air Pollution on Children Respiratory System in Lanzhou City. J Environ Health, 2008,25(10):873-876

[19]ZHOU Lan-dao, XIE Ji-shen, DONG Guang-hui. Effects of Indoor Environmental Pollution on Asthma and Asthma-Related Symptoms among Children from Baise City .Chinese Journal of Health Statistics, 2013,30(3):354-356.

[20] GUO H, Kw ok NH, Cheng HR, et al. Formaldehyde and volatile organiccompounds in Hong Kong homes: concentrations and impact factors. Indoor Air,2009,19(3):206-217.

[21]DING Wen-qing, LI Zheng-zhi, PAN Xiao-chuan, et al. Indoor Environmental Factors and Adults Asthma in Ningxia, China: a Case-Control Study. J Environ Health, 2007,24:149-150. 
[22]YUE Wei, JIN Xiao-bin, PAN Xiao-chuan, et al. Relationship between indoor air formaldehyde exposure and allergic asthma in adults. Chin J Public Health, 2004,20:904-906. 